\title{
Letter to the Editor: Bile Leak Reduction with Laparoscopic Versus Open Liver Resection: A Multi-institutional Propensity Score-Adjusted Multivariable Regression Analysis
}

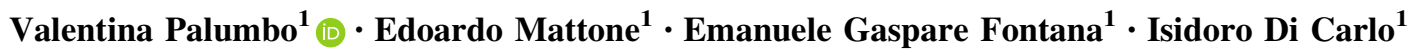

Accepted: 25 July 2020/Published online: 20 August 2020

(C) Société Internationale de Chirurgie 2020

\section{Dear Editor,}

We have read with great interest the article by Smith and co-workers [1], which focuses on decreases in the incidence of bile leaks after a minimally invasive approach to liver resection. After hepatectomy, bile leakage remains the most common cause of operative morbidity, increased costs, and disability. In the work by Smith et al., no bile leak testing was performed.

In Table 1 of the manuscript [1], the authors report the following proportions of patients who experienced bile duct leakage: 26/789 after open surgery and 13/599 after laparoscopic surgery. These data are acceptable; however, the readmission rates of 97/789 after open surgery and $39 / 599$ after laparoscopic surgery are difficult to understand, especially if all or part of these readmissions were related to bile leaks. The authors explain that laparoscopic liver resection is performed on a more limited scale; however, the extent of resection is not a limiting factor in a bile duct leak. Furthermore, ERCP is not suitable as a treatment for these patients, who already have a complication.

The routine use of bile leakage tests, such as the White test $[2,3]$, air leak test, and methylene blue test, improves the detection of open bile ducts, which are not easily displayed on the surface of the transection, and consequently, allows their intraoperative repair.

As evidenced from the literature, systematic use of bile leakage testing has been associated with a significant decrease in the incidence and severity of postoperative bile leakage complications [4].

Furthermore, the authors refer in their manuscript to the use of fibrin glue as a method to reduce the incidence of bile fistulas, although it has been proven that the use of fibrin glue does not prevent bile fistulas [5].

\section{References}

1. Smith AA, Monlezun DJ, Martinie J et al (2020) Bile leak reduction with laparoscopic versus open liver resection: a multiinstitutional propensity score-adjusted multivariable regression analysis. World J Surg 44:1578-1585. https://doi.org/10.1007/ s00268-019-05343-x

2. Nadalin S, Li J, Lang H et al (2008) The white test: a new dye test for intraoperative detection of bile leakage during major liver resection. Arch Surg 143:402-404

3. Di Carlo I, Barbagallo F, Toro A et al (2004) Hepatic resections using a water-cooled, high-density, monopolar device: a new technology for safer surgery. J Gastrointest Surg 8:596-600

4. Wang HQ, Yang J, Yang JY et al (2013) Bile leakage test in liver resection: a systematic review and meta-analysis. World $\mathrm{J}$ Gastroenterol 19:8420-8426

5. Nanashima A, Tobinaga S, Kunizaki M et al (2012) Does fibrin glue prevent biliary and pancreatic fistula after surgical resection? Hepatogastroenterology 59:1544-1547

Publisher's Note Springer Nature remains neutral with regard to jurisdictional claims in published maps and institutional affiliations.
Isidoro Di Carlo

idicarlo@unict.it

1 Department of Surgical Sciences and Advanced Technologies

"G.F. Ingrassia", Cannizzaro Hospital, General Surgery,

University of Catania, Via Messina 829, 95126 Catania, Italy 